\title{
Intraocular pressure measurement in sheep using an applanation tonometer
}

\author{
João Antonio Tadeu Pigatto ${ }^{1}$, Fabiana Quartiero Pereira ${ }^{2}$, Luciane Albuquerque $^{2}$, Luis Felipe Dutra Corrêa ${ }^{3}$, \\ Bernardo Stefano Bercht ${ }^{2}$, Paula Stieven Hünning ${ }^{3}$, Alberto Andre Ribeiro Silva ${ }^{2}$, \\ Luciana Vicente Rosa Pacicco de Freitas ${ }^{2}$
}

\begin{abstract}
The purpose of this study was to evaluate and establish the mean values of IOP in healthy adult sheep using an applanation tonometer. Information on age, sex, and breed was obtained for all animals included in this study. Twenty five healthy sheep (Ovis aries), of the same breed (Texel), male or female, with three years of age, received an ophthalmic examination in both eyes, including pupillary reflexes, Schirmer tear test, slit lamp biomicroscopy, and fluorescein staining. For all ophthalmic testing, animals were gently physically restrained, with no pressure in the jugular area and the eyelids were carefully open. IOP was measured by applanation tonometry (Tonopen XL). The same examiner performed the tonometry; measurements were taken three times for each eye, and their average was recorded as the IOP of the animal. Statistical analysis was performed using paired t-test and values of $P<0.05$ were considered significant. The mean intraocular pressure in the whole group of 50 eyes was of $16.36+/-2.19 \mathrm{~mm} \mathrm{Hg}$. The mean (SD) IOP in the right eye was of $15.96+/-2.02 \mathrm{~mm} \mathrm{Hg}$, while the mean (SD) IOP in the left eye was of $16.76+/-2.32 \mathrm{~mm} \mathrm{Hg}$. Significant differences in IOP were not found between right and left eyes. The applanation tonometer was adequate for measuring the intraocular pressure in sheep. Reference data will assist in diagnosing testing for ophthalmic disease in sheep, as ${ }^{1}$ well as promote further studies in this area.
\end{abstract}

Key words: Ovis aries, sheep, intraocular pressure, tonometry, glaucoma.

\section{RESUMO}

\section{Mensuração da pressão intraocular em ovinos, usando tonômetro de aplanação}

O objetivo deste estudo foi avaliar e estabelecer os valores de pressão intraocular (PIO) média, em ovinos adultos saudáveis, usando a tonometria de aplanação. Foram utilizados no estudo 25 ovinos saudáveis (Ovis aries), da raça Texel, machos ou fêmeas de três anos de idade. Foram realizados exames oftálmicos, incluindo: avaliação dos reflexos pupilares, teste lacrimal de Schirmer, avaliação com lâmpada de fenda e coloração com fluoresceína, em ambos os olhos de todos os animais. Para a realização dos testes oftálmicos, os animais foram contidos pelo mesmo auxiliar, sem pressão na região jugular e as pálpebras foram delicadamente abertas. A PIO foi aferida, utilizando-se o tonômetro de aplanação Tonopen XL, tendo sido todos os exames realizados pelo mesmo examinador. Foram realizadas três avalia-

Received 22/12/2010 and accepted for publication 26/10/2011

'Veterinarian, Doctor Science. Departamento de Medicina Animal, Faculdade de Veterinária, Universidade Federal do Rio Grande do Sul, Avenida Bento Gonçalves, 9090, 91540000, Porto Alegre, Rio Grande do Sul, Brasil. pigatto@ufrgs.br *Corresponding author

${ }^{2}$ Veterinarian. Departamento de Medicina Animal, Faculdade de Veterinária, Universidade Federal do Rio Grande do Sul, Avenida Bento Gonçalves, 9090, 91540-000, Porto Alegre, Rio Grande do Sul, Brasil. fabianaquartiero@hotmail.com, lucialbuquerque@hotmail.com.br, clinicaveterinariabetinho@hotmail.com, bernardo.bercht@gmail.com, luvrpf@yahoo.com.br

${ }^{3}$ Veterinarian, Master Science. Departamento de Medicina Animal, Faculdade de Veterinária, Universidade Federal do Rio Grande do Sul, Avenida Bento Gonçalves, 9090, 91540000, Porto Alegre, Rio Grande do Sul, Brasil. lfdcjeep@yahoo.com.br, paulastieven@yahoo.com.br. 
ções em cada olho e a média destas aferições foi considerada a PIO de cada olho do respectivo animal. Utilizou-se, para a análise estatística, o teste t pareado, sendo que valores de $\mathrm{p}<0.05$ foram considerados significativos. A pressão intraocular média de todo o grupo de 50 olhos foi $16.36+/-2.19 \mathrm{~mm} \mathrm{Hg}$. A IOP média do olho direito foi $15.96+/-2.02 \mathrm{~mm}$ $\mathrm{Hg}$, enquanto a do olho esquerdo foi 16.76 +/- $2.32 \mathrm{~mm} \mathrm{Hg}$. Não foram encontradas diferenças significativas entre a PIO do olho direito e esquerdo. Foi possível a avaliação da PIO em ovinos utilizando-se a tonometria de aplanação. Os dados deste trabalho irão ajudar na avaliação de doenças oftálmicas em ovinos, bem como promover novos estudos nessa área.

Palavras-chave: Ovis aries, ovelha, pressão intraocular, tonometria, glaucoma.

\section{INTRODUCTION}

Intraocular pressure (IOP) is determined by the production and drainage of aqueous humor (Slatter, 2005). The documentation of intraocular pressure for clinically normal animals is beneficial for diagnosing and monitoring an ocular disease (Ofri et al., 1998). Several methods have been described for measuring IOP in clinical and research situations, including indentation, applanation or rebound techniques (Bengtsson, 1972; Leiva et al., 2006; Jeong et al., 2007). The applanation tonometer is a hand-held instrument, ease of use, which provides IOP through a gentle touch on the cornea that resists deformation and presses against a $1.2 \mathrm{~mm}$-plunger housed on the tip. A strain gauge attached to the plunger converts the pressure into an electrical signal that is analyzed for acceptability and is digitally displayed (Passaglia et al., 2004).

The tonometer used in this study, Tonopen XL, has the same characteristics as the MacKay-Marg applanation tonometer, which is considered the golden standard in Veterinary Medicine, although it has no longer been manufactured (Rusanen et al., 2010).

Over the past years, sheep have become popular as production animals and they have also been identified as a model for steroid-induced ocular hypertension with $100 \%$ of susceptibility (Passaglia et al., 2004); therefore, it is important to know the mean intraocular pressure using an easy handling tonometer.

There are quite a few studies using applanation tonometry in animals (Priehs et al., 1990; Miller et al., 1990; Miller et al., 1991; Dziezyc et al., 1992; Passaglia et al., 2004; Candia et al., 2010; Gerometta et al., 2010; Ribeiro et al., 2010; Rusanen et al., 2010), but we found no reports on the assessment of the mean IOP in healthy sheep using the applanation tonometer Tonopen $\mathrm{XL}^{\mathrm{e}}$. The purpose of this study was to determine the mean IOP in healthy adult sheep using applanation tonometry with Tonopen $\mathrm{XL}^{\mathrm{e}}$.

\section{MATERIALS AND METHODS}

Twenty-five, healthy sheep (Ovis aries), with three years of age, male or female, were used in this study. All procedures were performed in compliance with the Association for Research in Vision and Ophthalmology Statement for the use of animals in researches on ophthalmic and vision research (National Research Council, 2011).

All sheep were under-went to ophthalmic examination based on pupillary reflexes, Schirmer tear test ${ }^{4}$ (STT), slit lamp biomicroscopy ${ }^{5}$, and fluorescein staining ${ }^{6}$. No abnormalities were found, though. For all ophthalmic testing, animals were manually restrained for a short time, with minimal pressure in the neck and eyelids. Thirty seconds after the application of anesthetic drops ${ }^{7}$, and having their eyelids manually retained open; the applanation tonometry ${ }^{8}$ was performed in both eyes (Figure 1). The data for both eyes of each animal were recorded. The first eye to be tested was determined randomly. The latex cover of the tonometer was replaced prior to the recording of each animal. Instrument calibration was also checked before the IOP measurement and the mean of three measurements was calculated and deemed. The same examiner performed the tonometry in all animals, which occurred between 13:00 and 17:00 pm. Means of intraocular pressures obtained from both eyes were compared by statistical data analysis using Tukey's test, and values of $P<0.05$ were considered significant.

\section{RESULTS}

Following the STT measurement, an ophthalmologic examination was performed. No abnormalities were

\footnotetext{
${ }^{4}$ Schirmer's ${ }^{\circledast}$ test Ophthalmos, São Paulo, SP, Brazil.

${ }^{5}$ Portable slit lamp, HSL 150 , Heine, Germany.

${ }^{6}$ Fluorescein collyrium $1 \% \oplus$, Ophthalmos, Sao Paulo, SP, Brazil.

${ }^{7}$ Anestalcon ${ }^{\oplus}$, Alcon, São Paulo, SP, Brazil.

${ }^{8}$ Tonopen ${ }^{\circledR}$ XL, Mentor Ophthalmic, INC:, Norwell, MA, USA.
} 


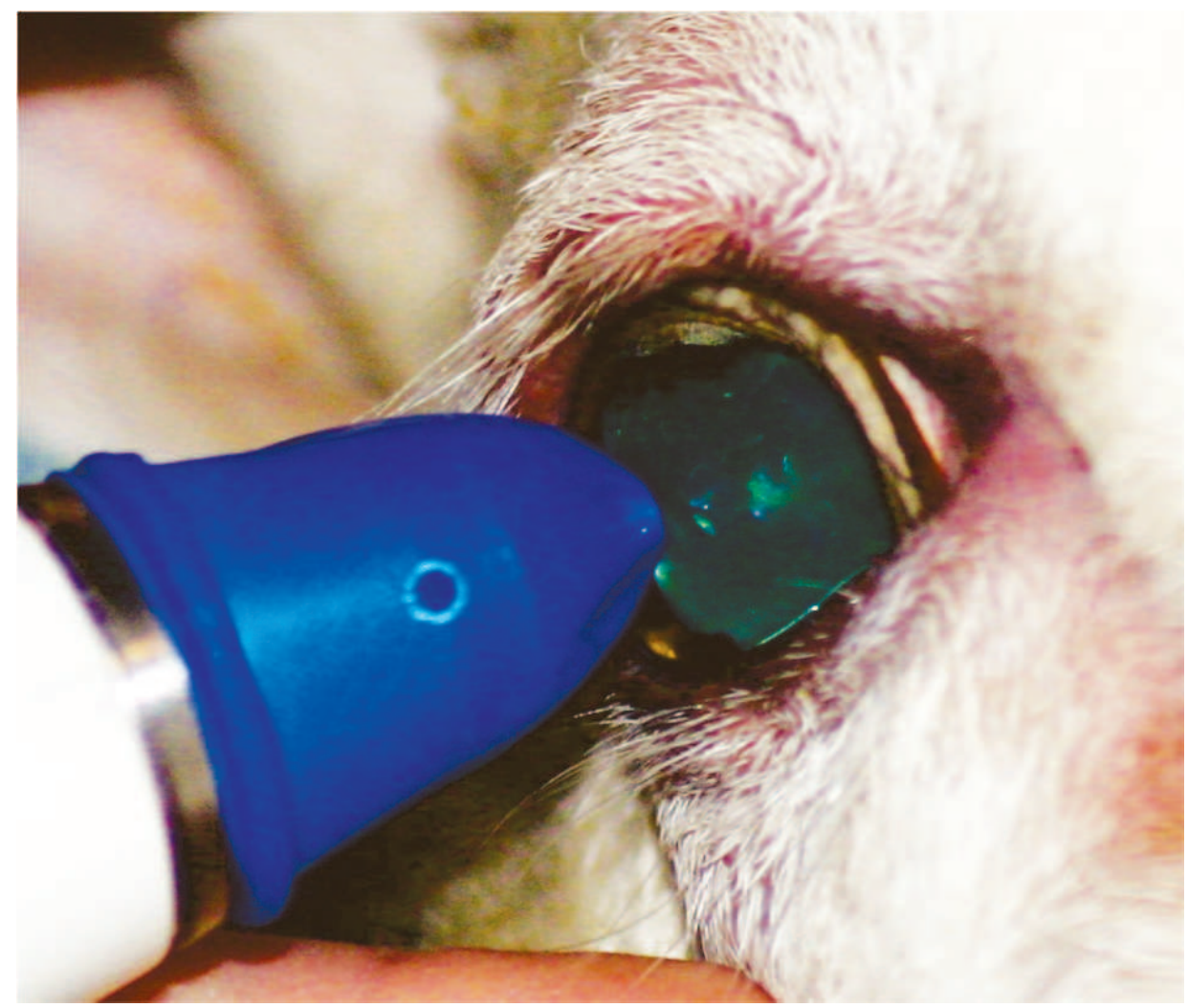

Figure 1. Evaluation of IOP in sheep using an applanation tonometer. Note the tip of the tonometer gentle touching the center of the cornea.

detected. The mean \pm SD of intraocular pressure in the whole group of 50 eyes was of $16.36+/-2.19 \mathrm{~mm} \mathrm{Hg}$. The mean $\pm \mathrm{SD}$ of intraocular pressure measurements were of $16.76 \pm 2.32 \mathrm{~mm} \mathrm{Hg}$ and $15.96 \pm 2.02 \mathrm{~mm} \mathrm{Hg}$ for the left and right eye, respectively. Significant differences were not detected between the left and right eye.

\section{DISCUSSION}

Intraocular pressure is a crucial parameter when diagnosing and managing ocular hypertension, various forms of glaucoma, and monitoring ocular diseases (Ofri et al., 1998; Biros et al., 2000).

However, as previously reported, there are great variations of IOP in different species, and the extrapolation of interspecies with normal pressures is not possible (Willis et al., 2000). The applanation tonometer has become the most popular instrument used for estimating IOP in many species, and being considered by some researchers as the most accurate and reliable method for estimating IOP in animals (Miller et al. 1991; Rusanen et al., 2010). The MacKay-Marg applanation tonometer, which is considered the golden standard in Veterinary Medicine, has no longer been manufactured. A portable Mackay-Marg-type tonometer (Tonopen) has been widely used among veterinary ophthalmologists and has been assessed in dogs, cats, horses, and in some extent in sheep (Miller et al.,
1990; Priehs et al., 1990; Miller et al., 1991; Dziezyc et al., 1992; Passaglia et al., 2004; Candia et al., 2010; Gerometta et al., 2010; Rusanen et al., 2010); however, a controlled study measuring the baseline IOP in healthy sheep, using applanation tonometry with Tonopen $\mathrm{XL}^{\mathrm{e}}$, has not yet been reported.

The advantages of applanation tonometry are the ease of use, portability of the instrument and less frequent calibration required. The main disadvantage is related to the need of instilling anesthetic eye drops before the IOP assessment.

All sheep included in this study received ophthalmic examination in both eyes and no abnormalities were detected.

The values of intraocular pressure may vary due to the devices model, the examiner's experience, the species studied, and also the time of the day (Gelatt \& Mackay, 1998). Other factors that alter the final IOP value include stress (Erb et al., 1998; Brody et al., 1999; Miyazaki et al., 2000), anesthesia (Murphy, 1985), choroidal blood flow, vitreous contents, sclera rigidity, orbicularis oculi muscle tension, and external pressure (Kniestedt et al., 2006). In this sense, a protocol of tests, in which measurements were assessed by the same examiner, was adopted. To reduce the stress, the measurements were performed on site and the same assistant properly restrained the animals 
for a short time, with minimal pressure in the neck and eyelids. Differences in IOP that are age related may exist. In dogs, it has been shown that IOP decreases with age (Gelatt \& Mackay, 1998). This study assessed only adult animals which does not allow us to establish a relationship between IOP and age groups. Differences in animal IOP related to sex seem only to occur in lions (Ofri et al., 1999) and have not been evaluated in this study. Furthermore, IOP changes associated with breed may occur, but they were not found in a large trial in 53 breeds of dogs (Gelatt \& Mackay, 1998); in our study, all animals were of the same breed.

In addition, in our study, all measurements were obtained between morning and noon in order to avoid circadian IOP variation, as shown in several species (Gelatt \& Mackay, 1998; Del Sole et al., 2007).

The following mean IOP were reported with applanation tonometry: $19.2 \pm 5.9 \mathrm{~mm} \mathrm{Hg}$ in dogs, $19.7 \pm$ $5.6 \mathrm{~mm} \mathrm{Hg}$ in cats, $23.3 \pm 6.89 \mathrm{~mm} \mathrm{Hg}$ in horses, $26.9 \pm 6.7$ $\mathrm{mm} \mathrm{Hg}$ in dairy cattle, $14.6 \pm 4.0 \mathrm{~mm} \mathrm{Hg}$ in elands, $11.9 \pm$ $3.3 \mathrm{~mm} \mathrm{Hg}$ in the deers, $13.10 \pm 0.35$ in llamas, $14.85 \pm 0.45$ $\mathrm{mm} \mathrm{Hg}$ in alpacas, $9.35 \pm 1.81 \mathrm{~mm} \mathrm{Hg}$ in Eurasian Eagle owls, $7.6 \pm 1.6 \mathrm{~mm} \mathrm{Hg}$ in Thomson gazelle and $24 \cdot 9 \pm 2 \cdot 0$ mm Hg in male lions (Miller et al., 1990; Gum et al., 1998; Ofri et al., 1999; Ofri et al., 2000; Willis et al., 2000; Ofri et al., 2001; Jeong et al., 2007; Rusanen et al., 2010). Our study showed that the mean IOP of sheep was lower than those of dogs, cats, horses, dairy cattle and lions, although it was higher than in the eland, deers, llamas, alpacas, owls and Thomson gazelle.

Research has shown that the mean IOP value in sheep using Perkin's applanation tonometer was of $10.6 \pm 1.4$ $\mathrm{mm} \mathrm{Hg}$ (Gerometta et al., 2009). This is lower than in our findings, highlighting the importance of establishing the mean values of IOP with a widely used applanation tonometer such as the Tonopen $\mathrm{XL}^{\mathrm{e}}$.

The accuracy of tonometers is determined in manometric studies. Manometric studies have been performed in sheep using Tonopen $\mathrm{XL}^{\mathrm{e}}$ and Perkin's tonometer (Passaglia et al., 2004; Gerometta et al., 2009). Measurements taken by Perkin's handheld tonometer were found having very good correlation, while Tonopen XL, it has been reported as overestimating IOP in subnormal pressure range and underestimating IOP in physiologic and high pressure range (Passaglia et al., 2004; Gerometta et al., 2009). In our study, manometric assessments were not performed, as the data are already available (Passaglia et al., 2004).

The mean intraocular pressure in the whole group of 50 eyes was of $16.36+/-2.19 \mathrm{~mm} \mathrm{Hg}$. Our results showed that significant differences in IOP were not found between right and left eyes, similarly to what was found in other studies (Gelatt \& Mackay 1998; Gerometta et al., 2009).

\section{CONCLUSION}

This study shows that the applanation tonometer is a useful device for measuring IOP in sheep. We hope this report will contribute to improve diagnostic capabilities of wildlife veterinarians as well as promote further studies in this area. Also, knowledge of normal intraocular pressure will aid in the diagnosis and monitoring of eye diseases in sheep.

\section{REFERENCES}

Bengtsson BO (1972) Comparison of schiøtz and goldmann tonometry in a population. Acta Ophthalmologica, 50:445457.

Biros DJ, Gelatt KN, Brooks DE, Kubilis PS, Andrew SE, Strubbe DT \& Whigham HM (2000) Development of glaucoma after cataract surgery in dogs: 220 cases (1987-1998). Journal of the American Veterinary Medical Association, 216:1780-1786.

Brody S, Erb C, Veit R \& Rau H (1999) Intraocular pressure changes: the influence of psychological stress and the Valsalva maneuver. Biological Psychology, 51:43-57.

Candia OA, Gerometta R, Millar JC \& Podos SM (2010) Suppression of corticosteroid-induced ocular hypertension in sheep by anecortave. Archives of ophthalmology, 128:338-343.

Del Sole MJ, Sande PH, Bernades JM, Aba MA \& Rosenstein RE (2007) Circadian rhythm of intraocular pressure in cats. Veterinary Ophthalmology, 10:155-161.

Dziezyc J, Millichamp N \& Smith W (1992) Comparison of applanation tonometers in dogs and horses. Journal of the American Veterinary Medical Association, 201:430.

Erb C, Brody S \& Rau H (1998) Effect of mental and physical stress on intraocular pressure-a pilot study. Klin Monatsbl Augenheilkd, 212:270-274.

Gelatt KN \& MacKay EO (1998) Distribution of intraocular pressure in dogs. Veterinary Ophthalmology, 1:109-114.

Gerometta R, Podos SM, Danias J \& Candia OA (2009) SteroidInduced Ocular Hypertension in Normal Sheep. Investigative Ophthalmology \& Visual Science, 50:669-673.

Gerometta R, Alvarez LJ \& Candia OA (2010) Effects of Sildenafil and Tadalafil on Intraocular Pressure in Sheep: Implications for Aqueous Humor Dynamics. Investigative Ophthalmology \& Visual Science, 51:313-319.

Gum GG, Gelatt KN, Miller DN \& Mackay EO (1998) Intraocular pressure in normal dairy cattle. Veterinary Ophthalmology, $1: 159-161$.

Jeong MB, Kim YJ, Yi NY, Park SA, Kim WT, Kim SE, Chae JM, Kim JT, Lee H \& Seo KM (2007) Comparison of the rebound tonometer (TonoVet $®$ ) with the applanation tonometer (TonoPen XL®) in normal Eurasian Eagle owls (Bubo bubo). Veterinary Ophthalmology, 10:376-379.

Kniestedt C, Lin S, Choe J, Nee M, Bostrom A, Stürmer J \& Stamper RL (2006) Correlation Between Intraocular Pressure, Central Corneal Thickness, Stage of Glaucoma, and Demographic Patient Data: Prospective Analysis of Biophysical Parameters in Tertiary Glaucoma Practice Populations. Journal of Glaucoma, 15:91-97.

Leiva M, Naranjo C \& Peña MT (2006) Comparison of the rebound tonometer (ICare $\left.{ }^{\circ}\right)$ to the applanation tonometer (Tonopen XL®) in normotensive dogs. Veterinary Ophthalmology, 9:17-21. 
Miller PE, Pickett JP \& Majors LJ (1990) Evaluation of two applanation tonometers in horses. American Journal of Veterinary Research, 51:935.

Miller PE, Pickett JP, Majors LJ \& Kurzman ID (1991) Evaluation of two applanation tonometers in cats. American Journal of Veterinary Research, 52:1917.

Miyazaki Y, Matsuo T \& Kurabayashi Y (2000) Immobilization Stress Induces Elevation of Intraocular Pressure in Rabbits. Ophthalmic Research, 32:270-277.

Murphy D (1985) Anesthesia and intraocular pressure. Anesthesia and analgesia, 64:520-530.

National Research Council (2011) Guide for the care and use of Laboratory animals. $8^{\text {a }}$ ed. Washington, D.C. The National Academies Press. 220p

Ofri R, Horowitz IH \& Kass PH (1998) Tonometry in three herbivorous wildlife species. Veterinary Ophthalmology, 1:2124.

Ofri R, Horowitz IH, Levison M \& Kass PH (2001) Intraocular pressure and tear production in captive eland and fallow deer. $\mathrm{J}$ Wildl Dis, 37:387-390.
Ofri R, Horowitz IH \& Kass PH (2000) How low can we get? Tonometry in the Thomson gazelle (Gazella thomsoni). Journal of Glaucoma, 9:187.

Ofri R, Shore LS, Kass PH \& Horowitz IH (1999) The effect of elevated progesterone levels on intraocular pressure in lions (Panthera leo). Research in Veterinary Science, 67:121-123.

Passaglia CL, Guo X, Chen J \& Troy JB (2004) Tono-Pen XL® calibration curves for cats, cows and sheep. Veterinary Ophthalmology, 7:261-264.

Priehs DR, Gum GG, Whitley RD \& Moore LE (1990) Evaluation of three applanation tonometers in dogs. American Journal of Veterinary Research, 51:1547.

Ribeiro AP, Piso DYT, Padua IRM, Silva ML \& Laus JL (2010) Intraocular pressure and tear secretion in Saanen goats with different ages. Pesquisa Veterinária Brasileira, 30:798-802.

Rusanen E, Florin M, Hässig M \& Spiess BM (2010) Evaluation of a rebound tonometer (Tonovet ${ }^{\circledR}$ ) in clinically normal cat eyes. Veterinary Ophthalmology, 13:31-36.

Slatter D (2005) Fundamentals of Veterinary Ophthalmology. $2^{\text {a }}$ ed. Philadelphia, W.B. Saunders. 403p.

Willis AM, Anderson DE, Gemensky AJ, Wilkie DA \& Silveira F (2000) Evaluation of intraocular pressure in eyes of clinically normal llamas and alpacas. American Journal of Veterinary Research, 61:1542-1544. 